\title{
Revisiting the restrictive/appositive distinction in Mandarin relative clauses: The confound of demonstratives
}

\author{
Yenan Sun \& Jackie Yan-ki Lai*
}

\begin{abstract}
This paper revisits the often-claimed correlation between the restrictive/appositive distinction in Mandarin relative clauses (RC) and their pre-/postdemonstrative position (Chao 1968; Huang 1998; Lin 2003 a.o.). We show that different uses of the demonstrative should be controlled for in establishing the correlation, a novel perspective which reconciles the conflicting claims noted in the literature. In particular, we argue that (i) only when the demonstrative is used deictically, the pre-/post-demonstrative position makes a difference such that predemonstrative RCs can only be appositive while post-demonstrative RCs can be either appositive or restrictive; and (ii) when the demonstrative is used anaphorically, the position of RCs does not determine its appositive/restrictive status. The new patterns can be accounted for by extending some analyses of strong definites (Elbourne 2005; Schwarz 2009; Jenks 2018) to Mandarin demonstratives, recognizing a structural distinction between the deictic use and the anaphoric use. The current proposal has implications for studies on demonstratives.
\end{abstract}

Keywords. Mandarin relative clauses; demonstratives; restrictive; appositive

1. Introduction. Mandarin relative clauses (RC) can co-occur with demonstratives (Dem) and typically either precede or follow the Dem. We refer to the two positions as the 'pre-Dem position' and the 'post-Dem position' henceforth. ${ }^{1}$
a. [RC ying-le bisai de] zhe (yi) wei xuesheng win-PERF game DE this one CL student
'this student (,) who won the game'
b. zhe (yi) wei [ $R C$ ying-le bisai de] xuesheng
this one CL win-PERF game DE student
'this student (,) who won the game'

While it is often claimed that whether a RC is restrictive or appositive correlates with its preDem/post-Dem position (Chao 1968; Huang 1998; Lin 2003; Constant 2011; Lin \& Tsai 2015, a.o.), different conclusions have been reached in the literature about what the correlation should be. One view holds that pre-Dem RCs are restrictive, and post-Dem RCs are appositive (Chao 1968; Huang 1998), while another holds that pre-Dem RCs are appositive, and post-Dem RCs are restrictive (Tsai 1994; Lü 1999). Some scholars even hold that all Mandarin relatives are restrictive (Zhang 2001; Shi 2010), and yet Lin (2003) holds that this is true unless the NP head is a proper name, in which case the RC is necessarily appositive.

\footnotetext{
* Many thanks to Karlos Arregi and three anonymous reviewers for their comments and suggestions and to audiences at the LSA 2019 meeting and the NASSLLI 2018 student session for their feedback. Thanks also go to Chang Liu, Han Yang and Franke Zhang for their judgments. Authors: Yenan Sun, University of Chicago (yenansun@chicago.edu) and Jackie Yan-ki Lai, University of Chicago (jyklai@uchicago.edu).

${ }^{1}$ Abbreviations in this paper: $\mathrm{CL}=$ classifier, $\mathrm{PERF}=$ perfective marker, $\mathrm{DE}=$ modificational marker.
} 
One reason for such mixed findings in the literature, which has been noted in some recent studies (Constant 2011; Del Gobbo 2010; Lin \& Tsai 2015; Del Gobbo 2017), is that the various tests used to diagnose restrictive/appositive distinction in English RCs are invalid in Mandarin. For instance, two common tests in English, as in (2) and (3), are argued to only be able to distinguish between non-integrated appositives (Cinque 2006, 2008b) and restrictives.

(2) Restrictive but not appositive RCs may modify universal quantifier phrases (Ross 1967)

a. *John congratulated every student, who won the game.

b. John congratulated every student that won the game.

(3) Appositive but not restrictive RCs may modify non-nominal phrases (Ross 1969)

a. Mary is honest, which John will never be.

b. *Mary is honest that John will never be.

However, Mandarin appositives are argued to be integrated (Del Gobbo 2010, 2017) just like the che/cui-type of appositive in Italian (Cinque 2006, 2008b) such that they would pass/fail exactly the same tests like (2-3) as restrictive RCs do. This might explain why many authors would consider all Mandarin RCs to be restrictive. On the other hand, Constant (2011) shows that appositives do exist in Mandarin, and there are indeed tests that can diagnose appositivity reliably, based on its unique semantic properties having to do with not-at-issue information.

This paper aims to point out another confounding factor, which has not yet been documented. We argue that there are at least two uses of demonstrative in language (Diessel 1999; Roberts 2003; Oshima \& McCready 2017): the deictic (or exophoric) use (which requires demonstration to the physical space) and the anaphoric use (which requires a linguistic antecedent in the discourse), and those uses potentially correlate with the restrictive/appositive distinction of RCs. The novel generalizations we are going to argue for are summarized in Table 1 .

\begin{tabular}{|l|l|l|}
\hline & Deictic Dem & Anaphoric Dem \\
\hline pre-Dem RC & only appositive & restrictive/appositive \\
\hline post-Dem RC & restrictive/appositive & restrictive/appositive \\
\hline
\end{tabular}

Table 1: Mandarin RCs that co-occur with demonstratives

The paper is organized as follows. Section 2 discusses the two different uses of demonstrative and applies tests (validated in Constant 2011 and Lin \& Tsai 2015) to support the new generalizations. Section 3 provides an analysis of them. Section 4 concludes and notes some implications of the proposed analysis.

\section{Demonstratives and its interaction with RCs.}

2.1 Two USES OF DEMONSTRATIVE. While there are many distinct uses of demonstrative (see Diessel 1999, Roberts 2003, Oshima \& McCready 2017, a.o. for discussion), this paper mainly focuses on the following two uses: the deictic use and the anaphoric use. When a demonstrative is used deictically, it is accompanied with some extralinguistic demonstration to the physical space in the discourse situation. For instance, (4) is uttered with the speaker's pointing to a person in their proximal/distant location (represented as the symbol '馆'), and 
the nominal expression which contains the demonstrative refers to that particular person.

\section{IT zhe/na wei xuesheng hen xingyun} this/that CL student very lucky

'This/that student is very lucky'

When a demonstrative is used anaphorically (Wolter 2004; Jenks 2018), the nominal expression that contains the demonstrative is coreferential with a noun phrase in the preceding discourse. Such a coreferential relation is indicated by co-indexation as in (5):

$$
\begin{aligned}
& \text { you [yi wei xuesheng } \left.]_{i} \text { ying-le bisai. [zhe/na wei xuesheng }\right]_{i} \text { hen xingyun } \\
& \text { have one CL student win-PERF game this/that CL student very lucky } \\
& \text { '[A student } \left.]_{i} \text { won the game. [This/that student }\right]_{i} \text { was very lucky' }
\end{aligned}
$$

In the next section, we show that these two uses actually affect the results of the diagnostics for the restrictive/appositive distinction in Mandarin RCs.

2.2 NEW GENERALizATIONS. In this section, we apply three tests that are validated in Constant (2011) and Lin \& Tsai (2015) to ascertain whether Mandarin RCs are appositive or restrictive.

The first test is Undeniability. The idea is that the content of appositive RCs is not atissue and thus it is not suspendible with epistemic riders (Potts 2005; Constant 2011). In (6-a), for example, the content of appositive RCs (marked in boldface) in the consequent of an ifconditional cannot be embedded in its antecedent. On the other hand, the content of restrictive RCs is usually considered to be presupposed (Comrie 1989) and thus it is embeddable in the if-conditional, as in (6-b).

(6) a. \#If John did win, then John, who won the game, was lucky.

b. If [a student $]_{i}$ did win, then [the student that won the game $]_{i}$ was lucky.

Now we apply the test to Mandarin. In (7), each utterance of the demonstrative is accompanied with a pointing gesture to someone in the speaker's proximal location to enforce the deictic use, and the result shows that the sentence with a post-Dem RC can be a felicitous continuation while the sentence with a pre-Dem RC cannot.

\section{(7) Deictic use}

ruguo 【客 zhe wei xuesheng queshi ying-le, ...

if this CL student indeed win-PERF

'If this student indeed won, ...'

a. \#[RC ying-le bisai de] $\mathbb{1}$ 客 zhe wei xuesheng hen xingyun

win-PERF game DE this CL student very lucky

'...this student, who won the game, was very lucky'

b. I实 zhe wei [ ${ }_{R C}$ ying-le bisai de] xuesheng hen xingyun

this CL win-PERF game DE student very lucky

'...this student who won the game was very lucky'

In the anaphoric use, on the other hand, both continuations in (8a) and (8b) are felicitous. 
(8) Anaphoric use

ruguo you $[\text { yi wei xuesheng }]_{i}$ queshi ying-le, ...

if have one CL student indeed win-PERF

'If [a student $]_{i}$ indeed won, ...'

a. $\quad[[R C \text { ying-le bisai de }] \text { zhe wei xuesheng }]_{i}$ hen xingyun win-PERF game DE this CL student very lucky

'...[this student who won the game $]_{i}$ was very lucky'

b. [zhe wei $[R C \text { ying-le bisai de] xuesheng }]_{i}$ hen xingyun

this CL win-PERF game DE student very lucky

'... [this student who won the game $]_{i}$ was very lucky'

The results show that when the demonstrative is used deictically, the pre-Dem RC can only be appositive since it is not deniable (thus failing the test), while the post-Dem RC can be restrictive; in contrast, when the demonstrative is used anaphorically, both pre-Dem and post-Dem RCs can be restrictive.

The second test is called Anti-backgrounding. Since appositive RCs (and supplements in general) typically introduce new information (Potts 2005), if their content is backgrounded, infelicity will rise due to redundancy. In contrast, the content of restrictive RCs as presupposed information will not exhibit any anti-backgrounding effect. The relevant contrast in English is shown as follows.

(9) a. Bill loves reading. \#When reporters interview Bill, who loves reading, he often talks about his books.

b. [A student $]_{i}$ loves reading. When reporters interview [the student that loves reading $]_{i}$, he often talks about his books.

Applying this test to Mandarin, as in (10)-(11), we obtain results similar to those from Test 1: for the deictic use of demonstrative, post-Dem but not pre-Dem RCs can be restrictive; for the anaphoric use of demonstrative, RCs in both positions can be restrictive.

(10) Deictic use

I客 zhe wei xuesheng ai dushu. 〈... a or b...〉 zuotian mai-le xuduo shu this CL student love reading yesterday buy-PERF many book

'This student loves reading. ... bought many books yesterday'

a. \#[RC ai dushu de] 馆 zhe wei xuesheng love reading DE this CL student

'...This student, who loves reading...'

b. I客 [zhe wei $\left[{ }_{R C} \text { ai dushu de }\right]_{i}$ xuesheng this CL love reading DE student

'...This student who loves reading...'

(11) Anaphoric use

[mou wei xuesheng $]_{i}$ ai dushu. $\langle\ldots$ a or b... zuotian mai-le xuduo shu some CL student love reading yesterday buy-PERF many book 
'[Some student $]_{i}$ loves reading. ... bought many books yesterday.'

a. $\quad\left[\begin{array}{lll}{ }_{R C} \text { ai } & \text { dushu de }\end{array} \text { zhe wei xuesheng }\right]_{i}$

love reading DE this CL student

'...[This student who loves reading $]_{i} \ldots$ '.

b. [zhe wei $[R C \text { ai dushu de] xuesheng }]_{i}$

this CL love reading DE student

'...[This student who loves reading $]_{i} . . . '$

Summarizing the results from Test 1 and 2, we can conclude that when a demonstrative is used deictically, there is an asymmetry between the pre-Dem RC and the post-Dem RC such that only the latter can be restrictive while the former must be appositive; when a demonstrative is used anaphorically, RCs in both positions can be restrictive.

\begin{tabular}{|l|l|l|}
\hline & Deictic Dem & Anaphoric Dem \\
\hline pre-Dem RC & *restrictive/appositive & can be restrictive \\
\hline post-Dem RC & can be restrictive & can be restrictive \\
\hline
\end{tabular}

Table 2: Results from Test 1 and Test 2

Notice that the two tests above only rule out appositives. Hence, for those RCs which pass them, even though we know that they can be restrictive, we are still certain whether they must be restrictive (as Constant 2011 notes). To figure this out, we need a test that can rule out restrictive RCs but allow appositive RCs. This third test is based on the RC's compatibility with root-level adverbs (Emonds 1979): only appositive, but not restrictive, RCs can host root-level adverbs like frankly, fortunately, as in (12).

(12) a. The student, who frankly has much time, should help you.

b. \#The student that frankly has much time should help you.

When we apply Test 3 to Mandarin, we obtain the following. ${ }^{2}$

Deictic use

wo hen xinshang ...

I very admire

'I admire ...'

a. [ ${ }_{R C}$ laoshishuo congbu songxie de] I窞 zhe wei xuesheng frankly never slack DE this CL student

'...this student, who frankly never slacks off.'

b. IT: zhe wei $[R C$ laoshishuo congbu songxie de] xuesheng this CL frankly never slack DE student

\footnotetext{
${ }^{2}$ An anonymous reviewer questions the validity of employing the Mandarin laoshishuo 'frankly' as a test. Notice that this adverb is in fact not compatible with restrictives. In contrastive contexts which force RCs to be restrictive, as in (i), the occurrence of laoshishuo is impossible.

(i) *women yinggai ba laoshishuo hen chou de ditan huancheng laoshishuo hen haokan de ditan. we should BA frankly very ugly DE mat replace.to frankly very pretty DE mat 'We should replace the mat that is frankly ugly with the mat that is frankly pretty.'
} 
'...this student, who frankly never slacks off.'

(14) Anaphoric use

$[\text { mou wei xuesheng }]_{i}$ ying-le bisai. wo hen xinshang ...

some CL student win-PERF game I very admire

'[Some student $]_{i}$ won the game. I admire ...'

a. $\quad\left[{ }_{R C}\right.$ laoshishuo congbu songxie de $]$ zhe wei xuesheng $]_{i}$

frankly never slack DE this CL student

'...[this student, who frankly never slacks off $]_{i}$ '

b. zhe wei $[R C$ laoshishuo congbu songxie de] xuesheng

this CL frankly never slack DE student

'...[this student, who frankly never slacks off $]_{i}$ '

The result shows that, regardless of how the demonstrative is used (deictically or anaphorically), both pre-Dem and post-Dem RCs that co-occur with it can be appositive.

To conclude this section, three tests were applied to Mandarin RCs that co-occur with demonstratives in both deictic and anaphoric uses, and the following picture emerges (Table $3)$. The next section proposes a formal analysis that accounts for it.

\begin{tabular}{|l|l|l|}
\hline & Deictic Dem & Anaphoric Dem \\
\hline pre-Dem RC & *restrictive/appositive & restrictive/appositive \\
\hline post-Dem RC & restrictive/appositive & restrictive/appositive \\
\hline
\end{tabular}

Table 3: Summary of the generalizations

3. Analysis. This section proposes a formal analysis that accounts for the generalizations on Mandarin RCs. We follow some recent treatments of demonstratives as strong (or anaphoric) definites (Jenks 2018; Elbourne 2005; Schwarz 2009) and make a novel point about the distinction between the deictic use and the anaphoric use of demonstrative. Before presenting the analysis, we first outline the assumptions about nominals and relative clauses in Mandarin, taking (15) as an illustration.

(15) zhe wei $\left[{ }_{R C}\right.$ ying-le bisai de] xuesheng

this CL win-PERF game DE student

'this student who won the game'

We follow Trinh (2011) and Jenks (2018) (which are based on works by Krifka (1995) and Chierchia (1998) among others) in taking (16) to be the structure of the noun phrase in (15), ignoring the $\mathrm{RC}$ for now. 
(16)

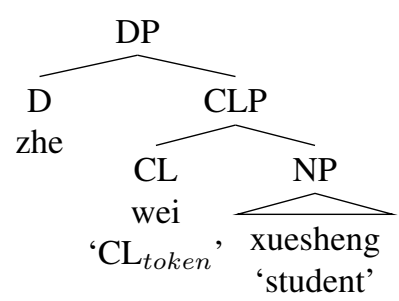

We also follow these authors in assuming a semantic model whose domain includes both atomic and plural individuals (Link 1983; Schwarzschild 1996), and kind-level atomic and plural individuals (Dayal 2004). Nouns denote a set of atomic and plural individuals, of both token-level and kind-level, while the token-level classifier $\left(\mathrm{CL}_{\text {token }}\right.$, e.g. wei) and the kind-level classifier $\left(\mathrm{CL}_{\text {kind }}\right.$, e.g. zhong) further restrict that set into a set of atomic token-level individuals and atomic kind-level individuals respectively, as in (17).

$$
\begin{array}{ll}
\text { a. } & x \in A T \text { if } \forall y[y \leq x \rightarrow(y=x)] \\
\text { b. } & \llbracket \mathrm{NP} \rrbracket=\llbracket \mathrm{xuesheng} \rrbracket=\lambda x \cdot \operatorname{student}(x) \\
\text { c. } & \llbracket \mathrm{CL}_{\text {token }} \rrbracket=\lambda P \lambda x . P(x) \wedge A T_{\text {token }}(x) \\
\text { d. } & \llbracket \mathrm{CLP} \rrbracket=\llbracket \text { wei xuesheng } \rrbracket=\llbracket \mathrm{CL}_{\text {token }} \rrbracket(\llbracket \mathrm{NP} \rrbracket)=\lambda x \text {.student }(x) \wedge A T_{\text {token }}(x)
\end{array}
$$

We assume a matching analysis for the syntax of Mandarin RCs (Aoun \& Li 2003), and de is treated as a modification marker that may attach to any modifier phrase in Mandarin (including AP, PossessiveP, etc), as in (18). Ultimately, the RC (together with $d e$ ) denotes a property and will compose with the nominal anchor via Predicate Modification, as in (19).

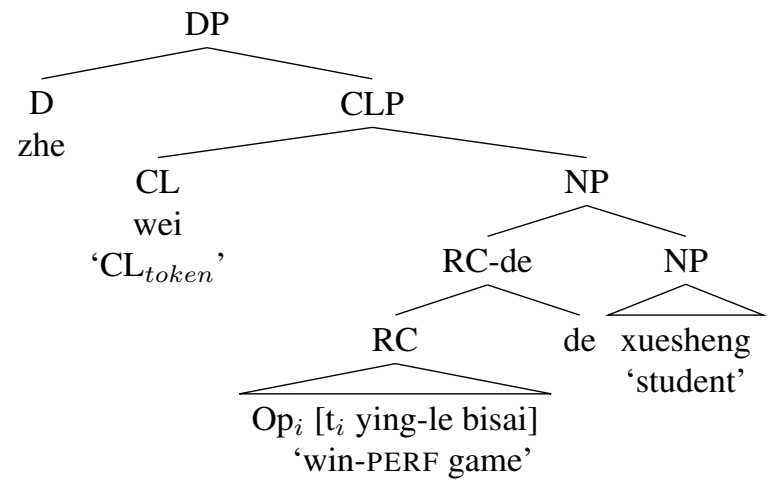

(19) $\quad$ a. $\quad \llbracket$ ying-le bisai de $\rrbracket=\lambda x$.win.the.game $(x)$

b. $\quad$ ying-le bisai de xuesheng $\rrbracket=\lambda x$.win.the.game $(x) \wedge \operatorname{student}(x)$

c. $\quad \llbracket C L P \rrbracket=\lambda x$.win.the.game $(x) \wedge \operatorname{student}(x) \wedge A T_{\text {token }}(x)$

We are now in a position to proceed to the core of our analysis: the structure and meaning of Mandarin demonstratives. We follow some recent studies that treat demonstratives as strong (or anaphoric) definites (Elbourne 2005; Schwarz 2009; Jenks 2018) ${ }^{3}$, which differ from the weak

\footnotetext{
${ }^{3}$ In those analyses cited above, the semantics of strong definites is taken to also contain a situation argument, so that the existence and uniqueness presuppositions hold relative to a particular (minimal) situation (Heim 1990;
} 
(or uniqueness-based) definite article in that syntactically an index occupies the specifier of the projection headed by the demonstrative and semantically, as in (22-a), the demonstrative has an extra argument slot, which can be saturated by an indexical property contributed by the index (via a type-shifting operation Pred). For instance, when a DP headed by the demonstrative is anaphorically linked to a previously-introduced discourse referent in (20), a relevant index takes up Spec,DP as in (21). Via Pred the index contributes an indexical property as in (22-b), which saturates the second argument of this, as in (22-d).

(20) English demonstrative 'this' as strong definites

[A student $]_{1}$ just came in. [This student $]_{1}$ seemed happy.

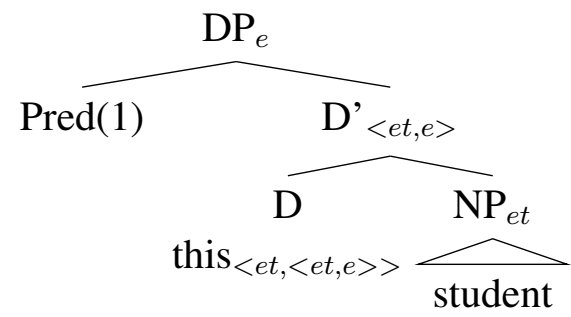
a. $\llbracket$ this $\rrbracket=\lambda P \lambda Q: \exists ! x[P(x) \wedge Q(x)] . \iota x[P(x) \wedge Q(x)]$
b. $\quad \llbracket \operatorname{Pred}(1) \rrbracket^{g}=\lambda x \cdot x=g(1)$
c. $\llbracket \mathrm{D}^{\prime} \rrbracket=\lambda Q: \exists ! x[\operatorname{student}(x) \wedge Q(x)] . \iota x[\operatorname{student}(x) \wedge Q(x)]$
d. $\quad \llbracket \mathrm{DP} \rrbracket=\exists ! x[\operatorname{student}(x) \wedge(x=g(1))] . \iota x[\operatorname{student}(x) \wedge(x=g(1))]$

Notice that under our classification, (20) exemplifies the anaphoric use of demonstrative. While the studies cited above do not explicitly discuss how the deictic use of demonstrative should be analyzed, some of them (Jenks 2018) do mention that the contribution of the demonstration (in the deictic use) can be taken to contribute some indexical property as well (e.g. a null index in Jenks' work). We basically agree with this intuition that the deictic use can be analyzed on a par with the anaphoric use, in that it also contributes some property. We further propose that the gesture (represented as $\delta$ ) actually occupies the Spec,DP position, and can be interpreted as follows.

$\llbracket \delta \rrbracket=\lambda x . L(x)$ where $L(x)$ is true iff $x$ is in a proximal location (relative to the speaker) demonstrated by the speaker's gesture $\delta .{ }^{4}$

Elbourne 2005, 2013). The situation argument is omitted in our analysis for simplicity, since it is not relevant to our discussion.

${ }^{4}$ The interpretation of the corresponding gesture of the distal 'that' would be the same excerpt that the 'proximal location' would be replaced by the 'distal location'. 


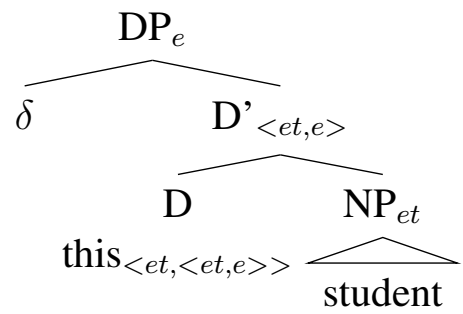

However, there is one crucial distinction between the deictic use and anaphoric use in our analysis: while Spec,DP is only optionally occupied by the referential index for the anaphoric use of demonstrative, that position is obligatorily occupied by the gesture $\delta$ for the deictic use. In other words, in the anaphoric use, Spec,DP can also be saturated by other phrases like AP, or a relative clause (Jenks 2018), as long as the properties contributed by them can satisfy the presupposition associated with the $\iota$-closure in (22).

This proposed distinction has the following consequence for pre-Dem RCs in Mandarin: when the demonstrative is used deictically, the pre-Dem RC can only be adjoined to DP but cannot occupy Spec,DP position, as it is always taken up the gesture $\delta$; when the demonstrative is used anaphorically, the pre-Dem RC can either be adjoined to DP or take up the Spec,DP position, since the referential index only optionally occupies Spec,DP.

Deictic demonstrative: Pre-Dem RCs can only adjoin to DP

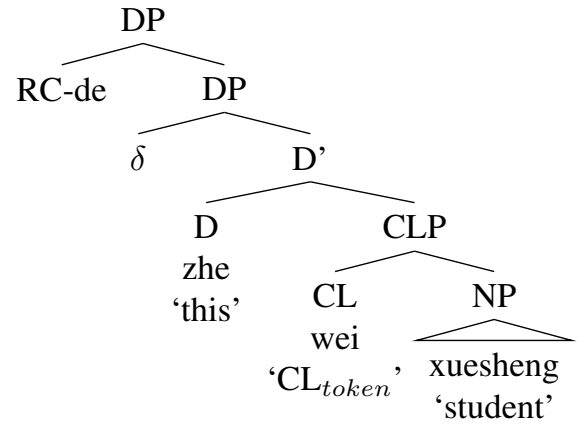

(25) Anaphoric demonstrative

a. $\quad$ Pre-Dem RCs adjoining to DP

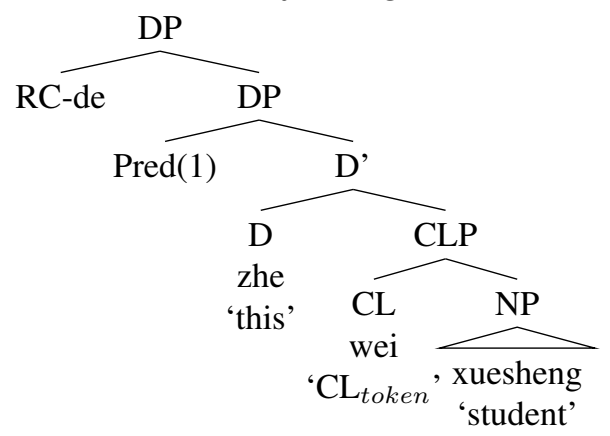

b. Pre-Dem RCs in Spec,DP

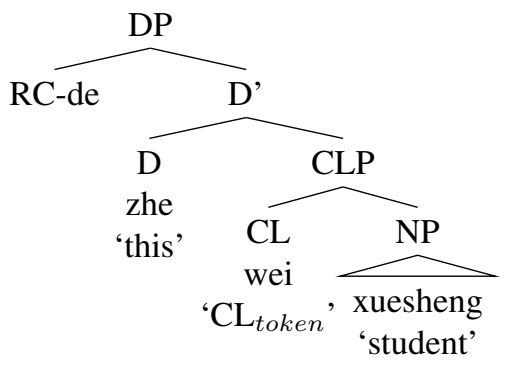


The structural position of pre-Dem RCs directly determines its semantic status ${ }^{5}$ : when it adjoins to the type $e \mathrm{DP}$, the relative clause (type et) cannot further restrict it and thus can only compose with it by CI application (Potts 2005). Adopting the CI rule and notations in Potts' system, we distinguish between the at-issue type and CI type by superscripts on types: $a$ tracks the at-issue dimension while $c$ tracks the CI dimension; and at-issue application and the CI application are separated by a dot between them, as illustrated in (26). ${ }^{6}$

[ $R C$ ying-le bisai de] [寞 zhe wei xuesheng win-PERF game DE this CL student

'this student, who won the game'

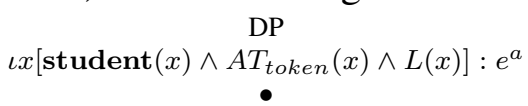

win.the.game $\left(\iota x\left[\operatorname{student}(x) \wedge A T_{\text {token }}(x) \wedge L(x)\right]\right): t^{c}$

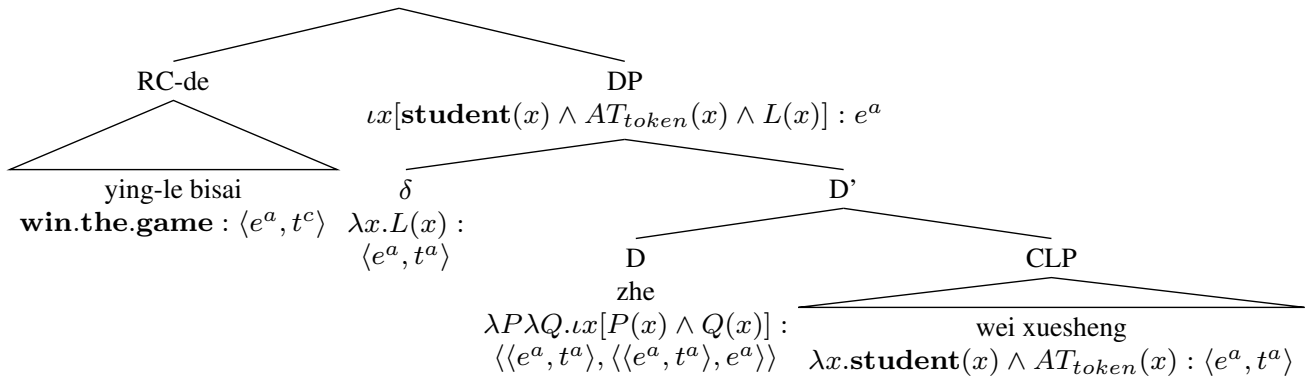

Since the content of the RC does not contribute to the at-issue dimension, it captures the fact that the pre-Dem RC with the deictic Dem can only be appositive.

When the RC occupies the Spec,DP position, it saturates the second argument of the demonstrative and thus contributes to the at-issue dimension, as shown in (27). It captures the fact that pre-Dem RCs with the anaphoric Dem can be restrictive.

[ $R C$ ying-le bisai de] zhe wei xuesheng win-PERF game DE this CL student

'this student who won the game'

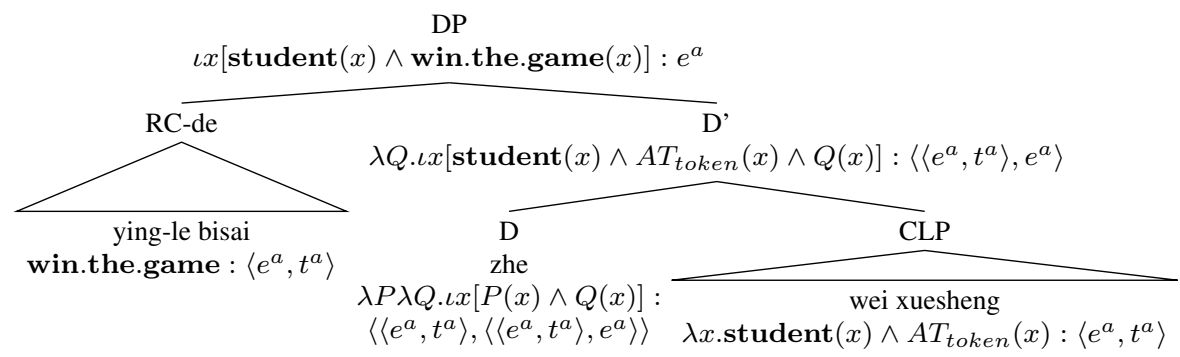

\footnotetext{
${ }^{5} \mathrm{We}$ assume that both pre-Dem RCs and post-Dem RCs are base-generated. There are accounts which derivationally relate the two (Zhang 2015; Constant 2011; Cinque 2008a), but to account for the differences between the pre-deictic-Dem RC and the pre-anaphoric-Dem RC, something else is necessary for blocking the restrictive RC for the deictic use while allowing it for the anaphoric use. We thank an audience member who raised this question.

${ }^{6}$ To make the derivation in (26) more readable, the presupposition part of the $\iota$-operator will be omitted henceforth.
} 
When the referential index saturates the Spec,DP position, the pre-Dem RC with the anaphoric Dem will adjoin to the DP, and thus be appositive.

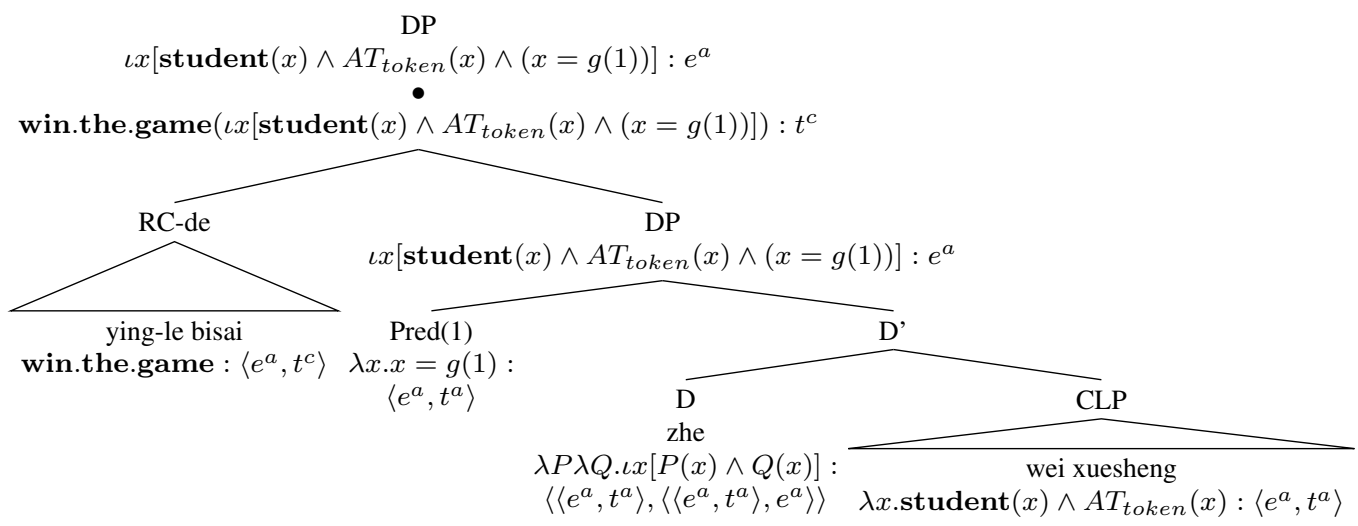

In sum, our proposal captures the fact that pre-Dem RCs with the deictic Dem can only be appositive (since the RC can only adjoin to DP), whereas the pre-Dem RCs with the anaphoric Dem can be either restrictive or appositive.

Let us now turn to post-Dem RCs. Since the distinction between deictic and anaphoric demonstratives only lies in the Spec,DP position, and the post-Dem RC attaches to NP, no difference concerning whether the RC can be appositive or restrictive will arise between the two uses, as desired. First, we derive the restrictive post-Dem RC. In this case, the RC attaches to NP as a modifier and the property denoted by the RC is interpreted intersectively with the property denoted by the NP. In other words, since the CLP, which contains the RC and NP, will saturate the first argument of the demonstrative, any semantic contribution from RC will contribute to the at-issue dimension as well as the NP and the classifier.

\section{Post-Dem RCs can be restrictive}

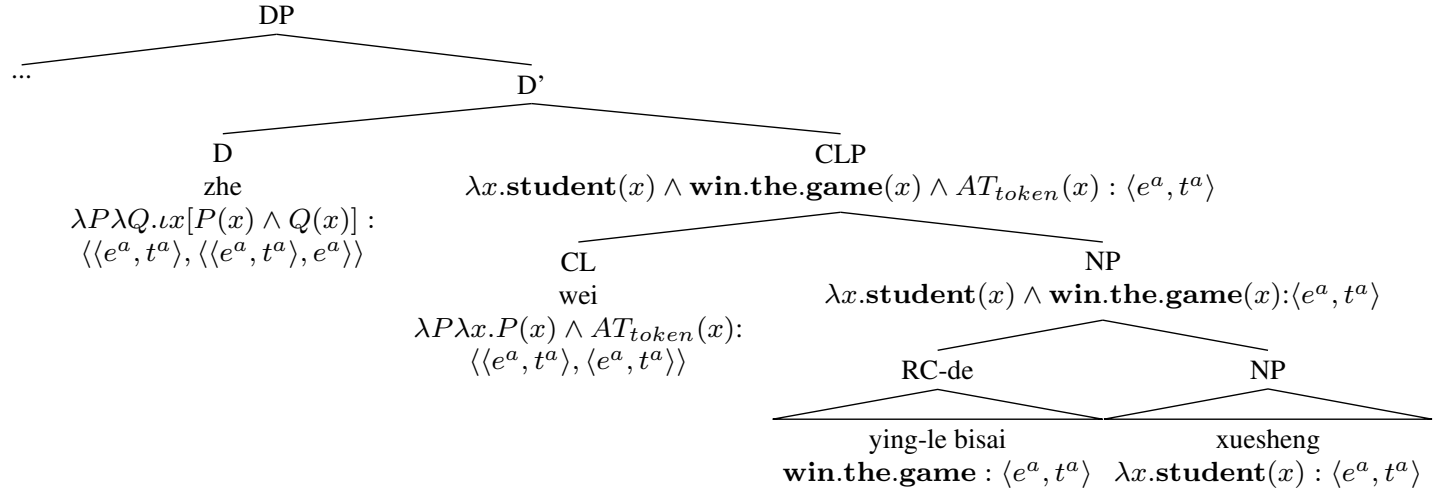

As for the appositive post-Dem RC, additional assumptions are needed in order to trigger the CI application. We follow Constant (2011) in adopting an approach towards appositive content, which can be taken to be propositional, with a context variable in its semantics. 


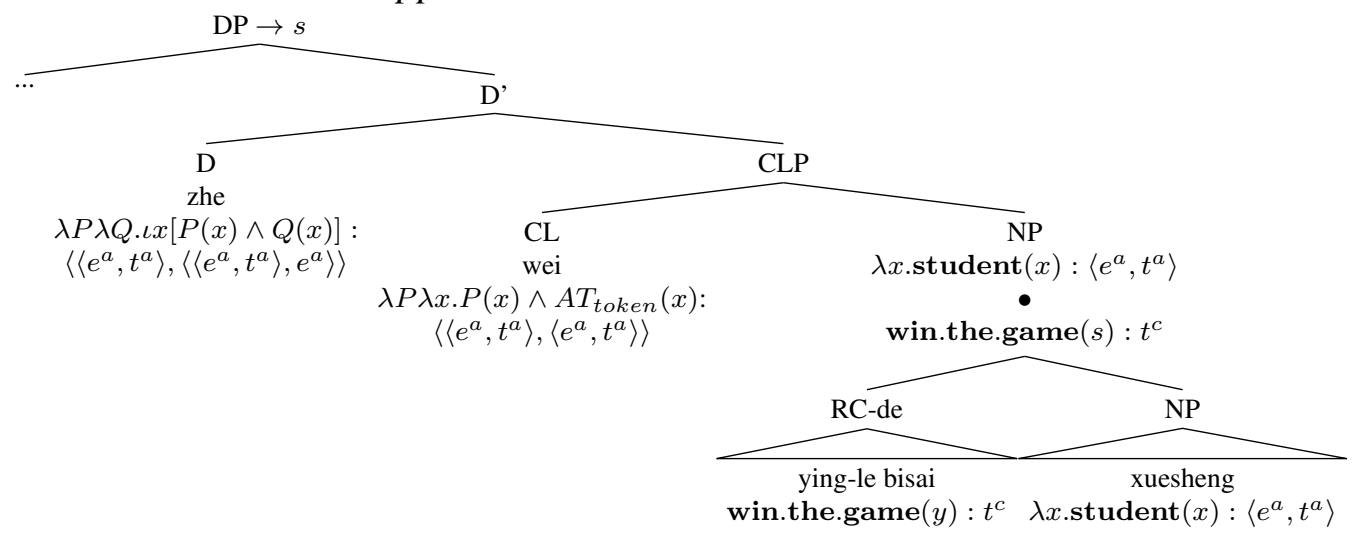

In other words, we have to abandon the assumption that RCs are always a 1-place predicate and assume that at least in some cases they can be propositional. In (30), the context variable takes the closest referent, i.e., the individual denoted by the DP, and in this way we derive the appositive post-Dem RC.

To summarize, by adapting the treatment of strong definites in Elbourne (2005), Schwarz (2009), and Jenks (2018) to Mandarin demonstratives, with the novel hypothesis that the deictic demonstrative differs from the anaphoric one in whether the specifier of a demonstrative can be occupied by an RC, we successfully account for all the generalizations about demonstrative co-occurring RCs in Mandarin.

4. Conclusions and beyond. This paper shows that different uses of the demonstrative are a factor in establishing the correlation between the restrictive/appositive status of a Mandarin RC and its pre-/post-Dem position. The pre-/post-Dem position matters only if the demonstrative is used deictically, which blocks restrictive RCs in the pre-Dem position. When the demonstrative is used anaphorically, the pre-/post-Dem position does not correlate with the restrictive/appositive distinction at all. We propose that the distinction is encoded in the structural difference between the deictic demonstrative and the anaphoric one: the specifier of the former must be occupied by a gesture, whereas the specifier of the latter can be occupied by different elements including the referential index, and modifiers like relative clauses and adjectives, as long as they contribute a relevant property semantically. This proposal extends previous analyses of strong definites (Elbourne 2005; Schwarz 2009; Jenks 2018), and shows how extralinguistic factors like demonstrative gesture can actively interact with linguistic structure.

\section{References}

Aoun, Joseph \& Yen-hui Audrey Li. 2003. Essays on the representational and derivational nature of grammar: The diversity of wh-constructions. Cambridge, MA: MIT press.

Chao, Yuan Ren. 1968. A grammar of spoken Chinese. Berkeley: University of California Press.

Chierchia, Gennaro. 1998. Reference to kinds across languages. Natural Language Semantics 6(4). 339-405. https://doi.org/10.1023/A:1008324218506.

Cinque, Guglielmo. 2006. Two types of appositives. Ms., Università di Venezia. 
Cinque, Guglielmo. 2008a. The prenominal origin of relative clauses. Handout.

Cinque, Guglielmo. 2008b. Two types of nonrestrictive relatives. Empirical Issues in Syntax and Semantics 7. 99-137.

Comrie, Bernard. 1989. Language universals and linguistic typology: Syntax and morphology. Chicago: University of Chicago Press.

Constant, Noah. 2011. Re-diagnosing appositivity: Evidence for prenominal appositives from Mandarin. CLS 47 .

Dayal, Veneeta. 2004. Number marking and (in)definiteness in kind terms. Linguistics and Philosophy 27(4). 393-450. https://doi.org/10.1023/B:LING.0000024420.80324.67.

Del Gobbo, Francesca. 2010. On Chinese appositive relative clauses. Journal of East Asian Linguistics 19(4). 385-417. https://doi.org/10.1007/s10831-010-9065-9.

Del Gobbo, Francesca. 2017. More appositives in heaven and earth than are dreamt of in your linguistics. Glossa 2(1). https://doi.org/10.5334/gjgl.14.

Diessel, Holger. 1999. Demonstratives: Form, function and grammaticalization. Amsterdam: John Benjamins.

Elbourne, Paul. 2013. Definite descriptions. Oxford: Oxford University Press.

Elbourne, Paul D. 2005. Situations and individuals. Cambridge, MA: MIT press.

Emonds, Joseph. 1979. Appositive relatives have no properties. Linguistic Inquiry 10(2). 211243.

Heim, Irene. 1990. E-type pronouns and donkey anaphora. Linguistics and Philosophy 13(2). 137-177. https://doi.org/10.1007/BF00630732.

Huang, C-T James. 1998. Logical relations in Chinese and the theory of grammar. Taylor \& Francis.

Jenks, Peter. 2018. Articulated definiteness without articles. Linguistic Inquiry 49(3). 501-536. https://doi.org/10.1162/ling a_00280.

Krifka, Manfred. 1995. 11 common nouns: A contrastive analysis of Chinese and English. In Gregory Carlson \& Francis Pelletier (eds.), The generic book, 398-411. Chicago: University of Chicago Press.

Lin, Jo-wang. 2003. On restrictive and non-restrictive relative clauses in Mandarin Chinese. Tsinghua Journal of Chinese Studies 33(1). 199-240.

Lin, Jo-Wang \& Wei-Tien Dylan Tsai. 2015. Restricting non-restrictive relatives in Mandarin Chinese. In Audrey Li, Andrew Simpson \& Wei-Tien Dylan Tsai (eds.), Chinese syntax in a cross-linguistic perspective, 100-127. Oxford: Oxford University Press.

Link, G. 1983. The logical analysis of plural and mass nouns: A lattice theoretic approach. In R. Bäuerle et al. (ed.), Meaning, Use and Interpretation of Language, 302-323. Berlin: de Gruyter.

Lü, Shuxiang. 1999. Xiushiyu [Modifiers]. In Ding Shengshu et al (ed.), Xiandai Hanyu Yufa Jianghua [Lectures on Modern Chinese Grammar], 42-55. Beijing: The Commercial Press.

Oshima, David Y. \& Eric McCready. 2017. Anaphoric demonstratives and mutual knowledge. The cases of Japanese and English. Natural Language and Linguistic Theory 35(3). 801837. https://doi.org/10.1007/s11049-016-9356-6.

Potts, Christopher. 2005. The logic of conventional implicatures. Oxford: Oxford University 
Press.

Roberts, Craige. 2003. Uniqueness in definite noun phrases. Linguistics and Philosophy 26(3). 287-350. https://doi.org/10.1023/A:1024157132393.

Ross, John Robert. 1967. Constraints on variables in syntax: MIT dissertation.

Ross, John Robert. 1969. Adjectives as noun phrases. In D.A. Reibel \& S.A. Schane (eds.), Modern Studies in English, 352-360. Englewood Cliffs: Prentice-Hall.

Schwarz, Florian. 2009. Two types of definites in natural language: University of Massachusetts Amherst dissertation.

Schwarzschild, Roger. 1996. Pluralities. Dordrecht: Kluwer.

Shi, Dingxu. 2010. Xianzhixing dingyu han miaoxiexing dingyu [Restrictive and descriptive modifiers]. Foreign Language Teaching and Research 42(5). 323-328.

Trinh, Tue. 2011. Nominal reference in two classifier languages. In Ingo Reich et al. (eds.), Sinn und Bedeutung 15, 629-644. Saarbrücken: Saarland University Press.

Tsai, Wei-Tien. 1994. On economizing the theory of A-bar dependencies: MIT dissertation. Zhang, Niina. 2001. On the absence of nonrestrictive relatives in chinese. ms. ZAS Berlin . Zhang, Niina Ning. 2015. Nominal-internal phrasal movement in Mandarin Chinese. The Linguistic Review 32(2). 375-425. https://doi.org/10.1515/tlr-2014-0026. 